\title{
ON THE TOTAL ROMAN DOMINATION IN TREES
}

\author{
Jafar Amjadi $^{1}$, Seyed Mahmoud Sheikholeslami \\ AND \\ MARZIEH Soroudi \\ Department of Mathematics \\ Azarbaijan Shahid Madani University \\ Tabriz, I.R. Iran
}

e-mail: \{j-amjadi;s.m.sheikholeslami;m.soroudi\}@azaruniv.ac.ir

\begin{abstract}
A total Roman dominating function on a graph $G$ is a function $f$ : $V(G) \rightarrow\{0,1,2\}$ satisfying the following conditions: (i) every vertex $u$ for which $f(u)=0$ is adjacent to at least one vertex $v$ for which $f(v)=2$ and (ii) the subgraph of $G$ induced by the set of all vertices of positive weight has no isolated vertex. The weight of a total Roman dominating function $f$ is the value $f(V(G))=\Sigma_{u \in V(G)} f(u)$. The total Roman domination number $\gamma_{t R}(G)$ is the minimum weight of a total Roman dominating function of $G$. Ahangar et al. in [H.A. Ahangar, M.A. Henning, V. Samodivkin and I.G. Yero, Total Roman domination in graphs, Appl. Anal. Discrete Math. 10 (2016) 501-517] recently showed that for any graph $G$ without isolated vertices, $2 \gamma(G) \leq \gamma_{t R}(G) \leq 3 \gamma(G)$, where $\gamma(G)$ is the domination number of $G$, and they raised the problem of characterizing the graphs $G$ achieving these upper and lower bounds. In this paper, we provide a constructive characterization of these trees.
\end{abstract}

Keywords: total Roman dominating function, total Roman domination number, trees.

2010 Mathematics Subject Classification: 05C69.

\section{REFERENCES}

[1] H. Abdollahzadeh Ahangar, J. Amjadi, S.M. Sheikholeslami and M. Soroudi, Bounds on the total Roman domination numbers, Ars Combin., to appear.

\footnotetext{
${ }^{1}$ Corresponding author.
} 
[2] H. Abdollahzadeh Ahangar, A. Bahremandpour, S.M. Sheikholeslami, N.D. Soner, Z. Tahmasbzadehbaee and L. Volkmann, Maximal Roman domination numbers in graphs, Util. Math. 103 (2017) 245-258.

[3] H. Abdollahzadeh Ahangar, M.A. Henning, V. Samodivkin and I.G. Yero, Total Roman domination in graphs, Appl. Anal. Discrete Math. 10 (2016) 501-517. doi:10.2298/AADM160802017A

[4] H. Abdollahzadeh Ahangar, T.W. Haynes and J.C. Valenzuela-Tripodoro, Mixed Roman domination in graphs, Bull. Malays. Math. Sci. Soc. 40 (2017) 1443-1454. doi:10.1007/s40840-015-0141-1

[5] J. Amjadi, S. Nazari-Moghaddam and S.M. Sheikholeslami, Global total Roman domination in graphs, Discrete Math. Algorithms Appl. 09 (2017) ID: 1750050. doi:10.1142/S1793830917500501

[6] J. Amjadi, S. Nazari-Moghaddam, S.M. Sheikholeslami and L. Volkmann, Total Roman domination number of trees, Australas. J. Combin. 69 (2017) 271-285.

[7] J. Amjadi, S.M. Sheikholeslami and M. Soroudi, Nordhaus-Gaddum bounds for total Roman domination, J. Comb. Optim. 35 (2018) 126-133. doi:10.1007/s10878-017-0158-5

[8] R.A. Beeler, T.W. Haynes and S.T. Hedetniemi, Double Roman domination, Discrete Appl. Math. 211 (2016) 23-29. doi:10.1016/j.dam.2016.03.017

[9] M. Chellali, T.W. Haynes, S.T. Hedetniemi and A.A. McRae, Roman $\{2\}$-domination, Discrete Appl. Math. 204 (2016) 22-28. doi:10.1016/j.dam.2015.11.013

[10] E.J. Cockayne, P.A. Dreyer, S.M. Hedetniemi and S.T. Hedetniemi, Roman domination in graphs, Discrete Math. 278 (2004) 11-22. doi:10.1016/j.disc.2003.06.004

[11] M.R. Garey and D.S. Johnson, Computers and Intractability: a Guide to the Theory of NP-Completeness (W.H. Freeman and Co., San Francisco, Calif., 1979).

[12] T.W. Haynes, S.T. Hedetniemi and P.J. Slater, Fundamentals of Domination in Graphs (Marcel Dekker Inc., New York, 1998).

[13] T.W. Haynes, S.T. Hedetniemi and P.J. Slater, Domination in Graphs: Advanced Topics (Marcel Dekker Inc., New York, 1998).

[14] M.A. Henning and S.T. Hedetniemi, Defending the Roman Empire-A new strategy, Discrete Math. 266 (2003) 239-251. doi:10.1016/S0012-365X(02)00811-7

[15] L.L. Kelleher and M.B. Cozzens, Dominating sets in social network graphs, Math. Social Sci. 16 (1988) 267-279. doi:10.1016/0165-4896(88)90041-8

[16] C.-H. Liu and G.J. Chang, Roman domination on strongly chordal graphs, J. Comb. Optim. 26 (2013) 608-619. doi:10.1007/s10878-012-9482-y 
[17] C.S. ReVelle and K.E. Rosing, Defendens imperium Romanum: a classical problem in military strategy, Amer. Math. Monthly 107 (2000) 585-594.

doi:10.1080/00029890.2000.12005243

[18] I. Stewart, Defend the Roman Empire!, Sci. Amer. 281 (1999) 136-138. doi:10.1038/scientificamerican1299-136

Received 14 August 2017 Revised 26 September 2017 Accepted 26 September 2017 